\title{
Risk: A Fundamental Barrier to the Implementation of Low Impact Design Infrastructure for Urban Stormwater Control
}

\author{
Joshua Olorunkiya $^{1}$, Elizabeth Fassman ${ }^{1} \&$ Suzanne Wilkinson ${ }^{1}$ \\ ${ }^{1}$ Department of Civil and Environmental Engineering, The University of Auckland, New Zealand \\ Correspondence: Joshua Olorunkiya, Department of Civil and Environmental Engineering, 20 Symonds Street, \\ The University of Auckland, Private Bag 92019, Auckland 1142, New Zealand. Tel: 64-212-628-688, \\ 64-937-375-99. E-mail: jolo006@aucklanduni.ac.nz
}

Received: June 9, 2012 Accepted: August 2, 2012 Online Published: September 1, 2012

doi:10.5539/jsd.v5n9p27 URL: http://dx.doi.org/10.5539/jsd.v5n9p27

\begin{abstract}
Rapid transformations of the urban landscape to cope with infrastructure needs have adverse consequences on the aquatic environments from urban stormwater runoff flows and the associated pollutants washed into the rivers and lakes. The implementation of low impact design (LID) infrastructure is considered a better approach to conventional management and control of urban runoff but has been slow, or non-existent, in many new urban cities. In addition to institutional, technological, social and economic barriers, risks and concern for contractual liabilities are identified as factors prohibiting uptake of low impact design. This article is based on findings from interviews; a survey and online questionnaire. The data obtained from the online survey was analyzed using non-parametric tests. First, the study showed risk as the most dominant factor inhibiting implementation of LID infrastructure. In addition, the results show a significant difference exists between professionals with LID implementation hands-on experience versus their counterparts with theoretical knowledge alone. Due to self-efficacy of professionals with practical experience, they are more inclined to favour and promote LID infrastructure, and hence possess better propensity for contractual liabilities risk taking. Summarily, the article proposes dissemination of relevant information among practitioners to improve LID knowledge apprehension and utilization. This will reduce perception of risk that will promote uptake. In addition, team collaboration with equitable contractual risk sharing for LID project planning and implementation is advocated.
\end{abstract}

Keywords: stormwater runoffs, LID, risks perceptions, hands-on experience, theoretical knowledge, decision making

\section{Introduction}

Urban landscapes are constantly undergoing transformations from the development of shelters and other essential infrastructure to cope with rural-urban migration and increasing world population. These transformations are not without their environmental consequences. Of concern in this article is stormwater runoff from impermeable surfaces such as roof tops, roads, and car parks, etc. Several studies have established the links between the collapse of healthy freshwater ecosystems in urban environments and stormwater runoff from such impervious surfaces (Konrad \& Booth, 2005; Ladson et al., 2006; Paul \& Meyer, 2001). Altered hydrologic regimes and the pollutants associated with urban runoff (such as hydrocarbons, heavy metals, sediments and other emerging contaminants) causes severe damage to aquatic ecosystems.

Urban runoff damage affects ecology functions, biological diversity, public health, recreation, economic activity, and general community well-being (Bannerman et al., 1993; Booth \& Jackson, 1997; Haile et al., 1999). Evidence suggests that high concentration of Lead, Zinc, Cadmium and other toxic pollutants in stormwater cause damage to ecosystems. In particular, an industrial substance like Nonylphenol is said to act as an endocrine disrupter that suppresses the production of sperms in fish decreasing fish production (Al-Bareeq, 1995). Furthermore, excessive phosphorus and nitrogen levels in waterways are also found to stimulate the growth of plants and algae, which can reduce dissolved oxygen levels that could harm the entire aquatic ecosystem when their natural habitat become 'dead zone' for lack of oxygen. The presence of E. coli and fecal coliform bacteria that get washed to the rivers and lakes also make them unsafe for swimming, forcing beach closures.

While the impacts of urban runoff may not easily be expressed in monetary value, damage to properties and loss of life has been reported across urban cities in recent times. In 2011, the Queensland flood was estimated to cost the 
Australian Government \$5.0billion dollars for the reconstruction works and a reduction in the Australian gross domestic product of $\$ 30$ billion dollars (Daley, 2011; White, 2011). In October 2011, a similar flood in Thailand was estimated to cost Lloyd's of London $\$ 2.2 \mathrm{bn}$ dollars in insurance claims from auto and electronics manufacturers alone. The Thailand disaster reported 800 lives lost and more than 10, 000 factories temporarily shut down and over 350, 000 workers were made redundant (Garside, 2012).

To minimise global impacts associated with stormwater runoff, a paradigm shift that encourages comprehensive holistic thinking, planning and management of urban stormwater runoff using low impact design (LID) is gaining attention. LID is a concept that aims to reduce the amount of untreated runoff discharged to surface water, keeping rainwater out of the sewer system, and preventing sewer overflows and reducing the need for conventional stormwater infrastructure (Kloss \& Calarusse, 2006). LID strategies involve the use of engineered infrastructure such as living (green) roofs, permeable pavements, and bioretention as well as non-engineered land use planning techniques such as minimizing or disconnecting impervious surfaces. LID techniques utilise the combination of engineered and non-engineered schemes to mimic natural processes to infiltrate, filter, evapotranspire, retain or detain runoff, or reuse stormwater on the site where it is generated (Michael, 2007). Providing opportunities for stormwater to be absorbed and treated by natural processes helps maintain groundwater supplies or reduce the disruption to surface waters. The implementation of LID projects is currently being promoted in USA, Australia, Canada, New Zealand and the United Kingdom through government led demonstration projects and other behaviour changing mechanisms such as incentive provisions and enforcement (Andre, 2008; Eason et al., 2003; Farrelly \& Brown, 2009; Shaver, 2009).

Despite numerous benefits demonstrated by LID infrastructure projects, the pace of uptake and implementation is still low. This is primarily due to the high level of uncertainty and perceived risk associated with the non-traditional concept for stormwater control. Barriers to LID infrastructure implementation can be categorised under risk, technical, regulatory, financial and community/social resistance (Abhold et al., 2011). Risks associated with insufficient technical knowledge of design strategies, limited contractors with hands-on experience, non-standardised construction procedures are some potential sources of resistance to LID implementation explored in this paper.

The starting point for choosing appropriate construction techniques (and for making assessment of professional negligence) is existing knowledge and accepted practice. Professionals and contractors are expected to be aware of published knowledge and standards and current good practice. In such situations, highly skilled contractors would normally draw attention to any requirement of the design which was contrary to good practice to attenuate joint risk liabilities. When there is no published knowledge and standards, lack of highly skilled contractors that can point out discrepancy from accepted standards, and non standardised construction procedures, potentials for professional negligence and contractual liabilities is limitless. Such liabilities stem from the warranties that are implied in construction contracts whether expressly mentioned or not. The implied terms in construction contracts include the expectation that the work will be executed using appropriate material and hence fit for the final purpose. Any breach of these terms (express or implied) is a cause of disputes in contract practice. Therefore, perception of risks and fear of contractual risk liabilities that may ensue from such uncertainties of long term performance constitute underlying factors inhibiting implementation of LID's. This issue has not been given adequate attention in the promotion of LID infrastructure implementation. For that reason, this article explores the following topics:

i. Establish the place of risk perception among other principal barriers influencing LID infrastructure adoption and implementation decisions among construction practitioners; and

ii. Explore the role practical experience plays on influencing contractual risk liability concerns among construction professionals on the adoption and implementation of LID infrastructure.

\section{Theoretical Framework}

According to Merriam-Webster Dictionary (1998), uncertainty is the quality or state of doubt; lack of conviction or knowledge especially about an outcome or result. On the other hand, risks are construed as events or outcomes with knowable probabilities. Furthermore, risks can be managed, while uncertainty is an event or a situation not expected or conceived to happen. New technologies are generally believed to involve higher degree of uncertainty and risks compared to conventional way of doing things. Though spanning two decades since it was first introduced, LID concepts still struggle with acceptance because of the difficulty to break old norms and practices. Therefore, the adoption and implementation of LID infrastructure for urban runoff management as a component of sustainable development are greatly hampered. 
Risk is fundamental to construction activities. In most cases, the primary tool for risk allocation between the contracting parties is a standard form of contract depending on the mode of construction procurement. Usually, construction contract documents are prepared by the client, where risks are apportioned between the client, design consultants and contractors typically charge a premium to cover risk, which has been found to account for at up to $30 \%$ of the project cost (Khan, 1998). The percentage is higher when an unconventional system such as the LID infrastructure is involved. This may be accountable for perceived higher cost of implementation among the community of practitioners, while in the real sense LID infrastructure has been proven to cost less compare with conventional infrastructure (Jeng-Bulloch, 2011; Shaver, 2009; Tetra Tech Inc, 2002, 2003a, 2003b). Due to limited LID implementation experience leading to design or construction mistakes, design consultants and contractors are often called upon to fix a post-construction problem which incurs additional costs. More so, inappropriate risk allocation in contracts has been identified as the cost of mistrust in the construction practice (Zaghloul \& Hartman, 2003) which often hinders innovation adoption.

LID's are considered risky and innovative for stormwater control. In order to understand the reluctance to incorporate innovation into construction, Rogers' diffusion of innovation decision is used as a theoretical framework. Rogers' diffusion of innovation decision covers: theory of risks perception, theory of reasoned action (TRA), theory of planned behaviour (TPB) and technology acceptance model (TAM).

Rogers (1995) defines an innovation as an idea, practice or object that is perceived as new by an individual, group, organisation or society. The decision to accept or reject an innovation is often made through a cost-benefit analysis with such choice affected by five innovation attributes: observability, relative advantage, compatibility, trialability and complexity (Rogers, 1995). Newness of or unfamiliarity with any innovation increases the magnitude of risks and uncertainty concerns, which in turn, reduces the rate of adoption and implementation (Blockley \& Godfrey, 2000; Lindner, 1987; Tsur et al., 1990). As such, the notion of risk perception has drawn interest from scholars in various fields due to its significant consequence on the technology adoption and implementation.

The term risk perception seeks to explain individual understanding and subjective evaluation of perceived risk (Wildavsky \& Dake, 1990). Subjective evaluations are influenced by factors such as the social context, individual's personal values, beliefs, education, experiences, risk taking propensity and stake in the outcome (Beecher et al., 2005). These factors constitute dynamic elements in innovation adoption decisions, acceptance and implementation. To appropriate knowledge within a social network means having a shared system of meaning that enables the other to understand and accept that knowledge (Chan \& Carol, 2001; Darr \& Pretzsch, 2008). The diffusion of knowledge therefore involves developing some level of shared group meaning as an essential element in risk perception. Sharing knowledge within the social network emphasises the importance of the cultivation of trust, norms and shared values amongst 'communities of practice' (Brown \& Duguid, 1991; 2001). In communities of practice, knowledge is constructed as individuals share ideas through collaborative mechanisms such as narration and joint work (Chan \& Carol, 2001; Kunz et al., 2010; Munkvoid, 2002; Vreede \& Briggs, 2005). It is this process of constructing meaning through joint endeavour that provides members of a social network with identity and cohesiveness the basis for knowledge diffusion (Tagliaventi \& Mattarelli, 2006). Through collaboration and knowledge sharing, familiarity is enhanced, perception of risk is reduced and ultimate LID technology adoption decision increases among stakeholders.

Theory of reasoned action (TRA) examines the relationship between individual expectations and the influence of other people as predictors of decision making (Fishbein \& Ajzen, 1975). An individual's intention to adopt LID infrastructure will be determined by two basic factors: one reflecting personal interests and one reflecting social influence. The personal factor will reflect the positive and negative evaluations of the ideas in term of the cost-benefit analysis and the opportunity costs. The social influence factor on the other hand refers to the individual's perceptions of the social pressures to adopt or conform to the principle of (in the case of LID's for urban stormwater control) sustainable development through adoption of innovative concepts. Social influence operates through a process of internalization, identification and compliance (Young, 2009). Internalization entails the acceptance of information from expert sources and integrates this information into one's cognitive system. Identification explicates the feeling of some bond with a social network and persists for as long as the network remains prominent (Valente, 1995). Finally, compliance is produced by rewards and punishments. The rewards may be in the form of incentive as an inducement, while punishment may take the use of legislation to enforce total or partial compliance. Theory of planned behaviour (TPB) is an extension of the TRA to account for conditions where individuals do not have complete control over their behaviour (Taylor \& Todd, 1995). TPB recognises that not all behaviour may be under an individual's volitional control, with behaviour ranging on a scale from complete control through to total lack of control (Ajzen, 1991; Ajzen \& Madden, 1986). The 
technology acceptance model (TAM) specifies the causal relationships between innovation characteristics, user perceptions (compatibility, perceived usefulness and ease of implementation) and behavioural impacts. Overall, the TAM provides an informative representation of the mechanisms by which technology design choices influence user acceptance (Davis, 1986).

TRA, TPB and TAM have been considered excellent attempts in understanding the influence of human behaviour in innovation adoption decisions (Dillon, 2001). But, both perceived usefulness and ease of use propounded by TAM constitutes post-implementation experience which does not accurately reflect the pre-implementation decisions that influences investment decision-making under condition of uncertainty. Because TAM constitutes post-implementation stage of Roger's diffusion theory, LID acceptance and implementation by stakeholders' will only increase if perception of risk of implementation diminishes.

\section{Methodology}

A two-stage research methodology of interviews with a survey and an online questionnaire was used in this research. A preliminary investigation through semi-structured interviews with 15 registered design or construction professionals yielded useful insights in the barriers to LID infrastructure implementation in Auckland, New Zealand. The interview discussions explored knowledge of LID principles, barriers to innovation adoptions in construction industry, risk management approaches, and related questions underpinned by the theories of TRA, TPB and TAM focused on LID infrastructure implementation. Immediately after the interview discussion, a survey requested participants to categorised pre-identified barriers to LID implementation under Technical, Economic, Risk, Institutional and Social factors. An explanation of these factors was provided to participants prior to administering the survey. The professionals consisted of architects, engineers, developers and contractors. Participants' years of experience, profession, state of acquaintance with LID infrastructure ("book" knowledge versus hand-on experience), and position are some of the individual characteristics influencing implementation decisions.

Results obtained from the preliminary investigation were used to develop an online questionnaire distributed to 350 professionals throughout New Zealand. The questionnaire was structured into three sections: demographic, adoption and risk related questions with responses in nominal and ordinal forms. The nominal responses were coded ' $\mathrm{Yes}=1, \mathrm{No}=2$ or Not Sure=3' while the ordinal questions were structured on a rank of 5,6 or 7 respectively based on the number of decision or compared preference variables. The online survey was extended to include other professionals like quantity surveyors, project managers and council officials with stormwater management portfolios to enhance generalisation of the findings to the targeted population. This adds significant benefits to the issue of generalisation and the representation of each subgroup according to their percentage of the overall population. The online questionnaire was considered the most suitable approach for administration because of the geographical dispersion of survey participants.

While the online portal (Survey Monkey) allowed the surveys to be sent out to specific email addresses earlier obtained through a purposive sampling, responses were not attached to the email address thus making the survey response completely anonymous. The purposive sampling approach to the sample selection enabled an industry-wide understanding of barriers and decision variables influencing LID infrastructure implementation. Elicitation of differences between professional organisation and individual personal characteristics explored in the study provide directions and further insights into incentive mechanisms design based on public preferences to induce behavioural control to advance the state of LID infrastructure implementation in line with the theory of TRA and TPB.

The response rate for the online survey was 168 out of sample size of 350 participants contacted, representing $48 \%$. The response rate exceeded the normal rate of $20-30 \%$ for most online surveys (Cook et al., 2000). This was due to pre-contact phone conversation seeking participants' consent before the survey link was sent. Responses that met data quality criteria reduced the final sample size to 133. The data quality criteria involved the detection and elimination of cases with either response bias or response style to ensure both internal and external reliability and validity of findings. Response bias identified during the data screening includes voluntary item omission and inconsistent pattern of response Since missing data are inevitable in any survey, multiple imputation (MI) techniques were run five times with maximum iteration of fifty to fill-in the missing values prior data analysis (Little \& Rubin, 2002; Rubin, 1976; Schafer \& Graham, 2002; Sinharay et al., 2001) using SPSS version 19 .

Significant statistical relationships and differences were tested using nonparametric procedures of Kruskal-Wallis (K-W), and Kolmogorov-Smirnov (K-S) test. The choice of the non parametric tests was determined by the qualitative nature of the data set which consisted of dependent and independent variables of 
nominal and ordinal types. Therefore, using parametric statistics to analyse such data would be a violation of statistical principles (Agresti, 1996; Field, 2006; Tabachnick \& Fidell, 2007). As the statistical distribution of responses between groups with LID hands-on experience versus the groups with theoretical knowledge alone cannot be assumed with a fair degree of certainty, the nonparametric K-S test was the most suitable to assess any significant difference (Siegel \& Castellan, 1988). The K-S test can pick up differences between the groups regardless of the nature of differences, since it was not known beforehand how such differences between the groups might manifest, because a two-sided K-S test is sensitive to any kind of difference in the distribution of two samples: difference in location (central tendency), dispersion, asymmetry, etc. (Siegel \& Castellan, 1988). It was hypothesized that an individual's length (duration) of experience as a practitioner would influence LID infrastructure implementation decisions. The K-W test was used to test for significant differences between respondents (grouped according to each individual's years of experience) and five suggested major barriers to LID implementation. The principal barriers were: technical factor, economic factor, risk factor, social factor, and institutional factor. Differences were assessed with a 99\% confidence interval and $\alpha \leq 0.05$ level of significance.

One of the topics the paper set out to explore is the role practical experience on LID infrastructure implementation plays on influencing contractual risk liability concerns among construction professionals on the adoption and implementation of LID infrastructure. Before the statistical test between groups, Kendall's concordance analysis was used to assess the extent of agreement of within-group ratings of the barriers influencing LID infrastructure implementation decisions (Howell, 2010). The non-significance result obtained from the K-W test for exploring the significant difference between principal barriers to LID implementation was followed up with a pairwise comparison to further investigate if the non-significance result obtained under risk as a factor was a reality of the test sample or a chance occurrence.

\section{Results}

The results of this study are presented in two sections based on the methodology approach. First, the analysis of the pilot study is presented. Figure 1 gives the full description of the barriers to LID implementation explored; Figure 2 identifies the number of responses based on practitioners' perceptions while Figure 3 gives a summary of the categorical principal factors. Second, findings from the statistical analysis from the larger online survey are presented from Tables 1 to 4 .

\subsection{Survey Result}

\section{Identified Barriers to LID Implementation for Stakeholders Classifications}

$\begin{array}{ll}\text { FL } & \text { Fear of Liability } \\ \text { RSN } & \text { Reluctance to try something new } \\ \text { LET } & \text { Lack of educa tion and training } \\ \text { LDE } & \text { Limited design example } \\ \text { LCC } & \text { Life cycle costing } \\ \text { PP } & \text { Public perception } \\ \text { CER } & \text { Compatibility with existing requirements } \\ \text { MCE } & \text { No clear economic incentives for using LID } \\ \text { SHP } & \text { Semi-arid area hydrology/poorly drained soil } \\ \text { MD } & \text { Maintenance and durability } \\ \text { SWN } & \text { Standing water nuisance } \\ \text { FRP } & \text { Fear of lengthening review process } \\ \text { CMR } & \text { Conflict with municipal code requirements } \\ \text { ECD } & \text { Expansive soils and construction defect la wsuit } \\ \text { HGT } & \text { High groundwater table } \\ \text { OAE } & \text { Other alternatives are easier }\end{array}$

Figure 1. Full description of barriers to LID implementation explored 


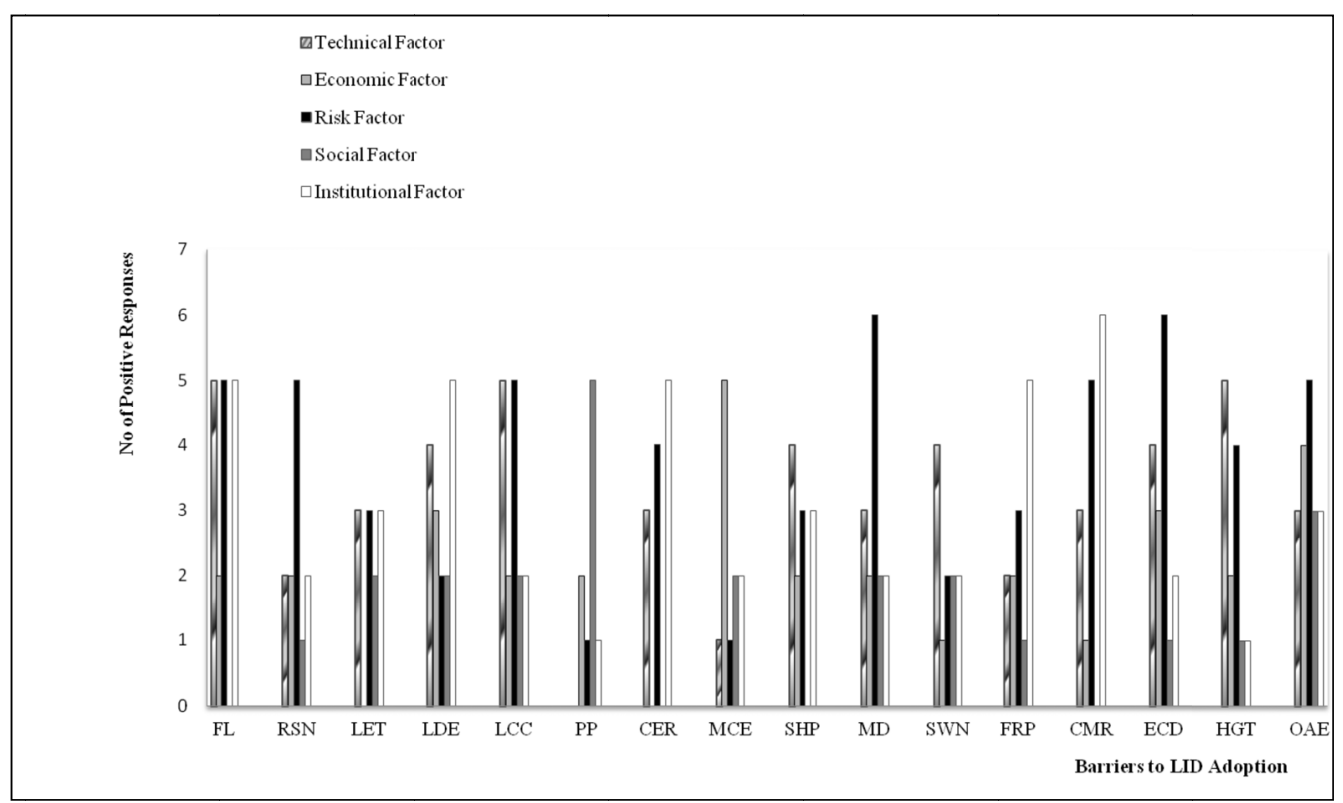

Figure 2. Practitioners' perception of LID implementation barriers.

The maximum response for any category is 15 .

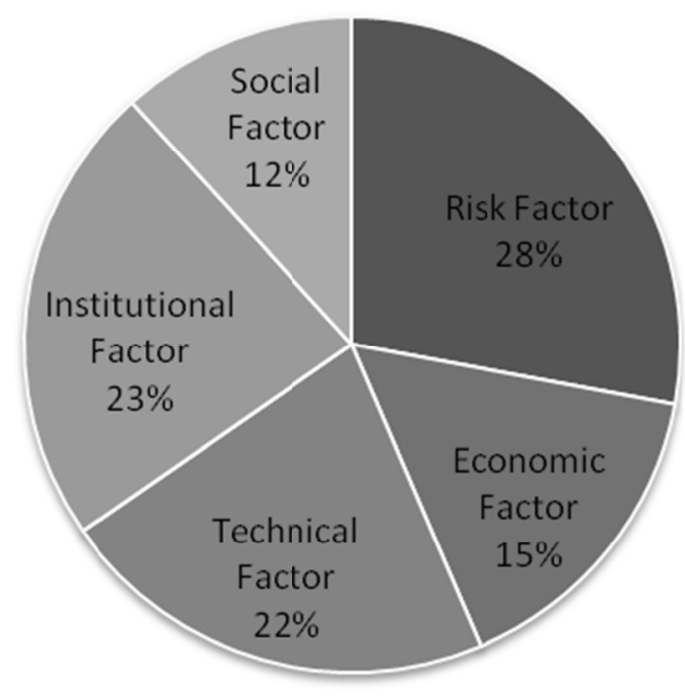

Figure 3. Categorical barriers to LID adoption

Risk factors consist of the fears of the unknown and uncertainties involved in trying new ideas, limited design examples, possible financial loss and contractual liabilities. Institutional factors consist of compliance with legislative regulations and codes such as the Resource Management Act (RMA) which regulates development activities in New Zealand due to potential impacts on the environment. Codes and regulations have not kept pace with the development of new techniques such as LID and therefore are a barrier to adoption. Technical factors primarily concern lack of design manuals, guides and other standards that can easily be utilised by design consultants and contractors. Economic factors are concerns about life cycle costing as well as durability of LID installation components, while the social factor describes individual resistance to an unconventional way of doing things and the reluctance to change status quo. Reluctance to try something new, maintenance and durability, expansive soils and construction challenges, and the perception that other alternatives constitute major 
barriers deemed risk elements. This supports findings from previous studies about uncertainty and the innovation adoption life cycle in other disciplines (Rogers, 1995; Wildavsky \& Dake, 1990).

\subsection{Online Survey Results}

Table 1. Distribution of respondents

\begin{tabular}{lcccccc}
\hline \multirow{2}{*}{ Organisation Profession } & \multicolumn{4}{c}{ Years of Exp. per Respondent } & \multirow{2}{*}{ Total } \\
& $0-5 \mathrm{yr}$ & $6-10 \mathrm{yr}$ & $11-15 \mathrm{yr}$ & $16-20 \mathrm{yr}$ & $>21 \mathrm{yr}$ & \\
\hline Architecture & 4 & 4 & 5 & 3 & 4 & $\mathbf{2 0}$ \\
Engineering & 3 & 8 & 6 & 5 & 7 & $\mathbf{2 9}$ \\
Land/ Building Developer & 4 & 1 & 2 & 1 & 3 & $\mathbf{1 1}$ \\
Contracting & 3 & 3 & 1 & 2 & 7 & $\mathbf{1 6}$ \\
Regulatory Authority & 7 & 4 & 6 & 4 & 3 & $\mathbf{2 4}$ \\
Other Consultancy & 7 & 1 & 8 & 7 & 10 & $\mathbf{3 3}$ \\
$\quad$ Total & $\mathbf{2 8}$ & $\mathbf{2 1}$ & $\mathbf{2 8}$ & $\mathbf{2 2}$ & $\mathbf{3 4}$ & $\mathbf{1 3 3}$ \\
\hline
\end{tabular}

Table 2. Kruskal-Wallis test for comparing the significant differences between respondents years of experience and five suggested major barriers to lid infrastructure implementation

\begin{tabular}{llllll}
\hline & $\begin{array}{l}\text { Technical } \\
\text { Reqmnts }\end{array}$ & $\begin{array}{l}\text { Economic } \\
\text { Reqmnts }\end{array}$ & $\begin{array}{l}\text { Risk/Legal } \\
\text { Liabilities }\end{array}$ & $\begin{array}{l}\text { Public } \\
\text { Perception }\end{array}$ & $\begin{array}{l}\text { Legislative } \\
\text { Reqmnts }\end{array}$ \\
\hline Chi-Square & 15.75 & 11.355 & 6.525 & 20.072 & 10.922 \\
Df & 4 & 4 & 4 & 4 & 4 \\
Monte Carlo Sig. & $.003^{\mathrm{a}}$ & $.020^{\mathrm{a}}$ & $.163^{\mathrm{a}^{*}}$ & $.000^{\mathrm{a}}$ & $.031^{\mathrm{a}}$ \\
\hline *Risk/legal liability statistically non- significant at $p>0.05$ & Grouping Variable: Individual years of Experience
\end{tabular}

Table 3. Post-hoc pairwise comparisons of test of non-significant for Risk/Legal liabilities

\begin{tabular}{ccc}
\hline $\begin{array}{c}\text { Respondents' Years of } \\
\text { Experience }\end{array}$ & $\begin{array}{c}\text { Mann- Whitney Significance value for the pairwise } \\
\text { comparison }\end{array}$ & $\begin{array}{c}\text { Bonferroni Adjustment } \\
\text { Value }\end{array}$ \\
\hline $0-5$ vs. $6-10$ & 0.336 & 0.0336 \\
$0-5$ vs. $11-15$ & 0.903 & 0.0903 \\
$0-5$ vs. $16-20$ & 0.094 & 0.0094 \\
$0-5$ vs. $\geq 21$ & 0.513 & 0.0513 \\
$6-10$ vs. $11-15$ & 0.362 & 0.0362 \\
$6-10$ vs. $16-20$ & 0.49 & 0.049 \\
$6-10$ vs. $\geq 21$ & 0.158 & 0.0158 \\
$11-15$ vs. $16-20$ & 0.152 & 0.0152 \\
$11-15$ vs. $\geq 21$ & 0.456 & 0.0456 \\
$16-20$ vs. $\geq 21$ & 0.026 & $0.0026^{*}$ \\
\hline
\end{tabular}

*Statistically significant at $P<0.005$

The statistical analysis is intended to identify if there is a difference in perceived barriers to LID implementation according to respondents' professional years of experience. According to Table 2, all professional groups identified risk as a fundamental barrier, regardless of level of experience $(\mathrm{p}=0.163)$. For all other principal barriers, an individual's decision to implement LID infrastructure is significantly influenced by respondents' years of experience $(0.001 \leq \mathrm{p} \leq 0.031)$. 
Table 3 shows the pairwise significance values and the Bonferroni significance values after correction for Type 1 errors at $\alpha=0.005$ at 10 pairwise post-hoc tests. Thus, the statistical non-significant value obtained for risk/legal liabilities in the K-W test can be inferred as not being a chance occurrence but a reality of the target population. Therefore, irrespective of individual years of experience, concern for risk in decision making is not significantly different when it comes to technology adoption decisions. Furthermore, the finding from the online survey analysis follows similar trend found in the pilot study survey shown in Figure 3.

Table 4. Kolmogorov-Smirnov test for state of acquaintance (hands-on experience and "book" knowledge) as factors influencing practitioners' concern for contractual liabilities

\begin{tabular}{|c|c|c|c|}
\hline & & Risk/ Legal Liabilities & $\begin{array}{l}\text { Exposure to liability/ } \\
\text { Chances of failure }\end{array}$ \\
\hline \multirow{3}{*}{ Most Extreme Differences } & Absolute & 0.159 & 0.168 \\
\hline & Positive & 0.046 & 0.168 \\
\hline & Negative & -0.159 & -0.057 \\
\hline Kolmogorov-Smirnov Z & & 1.751 & 1.846 \\
\hline Monte Carlo Sig. (2-tailed) & & $.002^{*}$ & $.001^{*}$ \\
\hline
\end{tabular}

The K-S test was used to explore the difference between practitioners with practical LID experience and those with "book" knowledge alone about their concerns for the fear of contractual liabilities. The results in Table 4 indicate a statistically significant difference exist between the respondents' based on their respective 'state of acquaintance' with LID infrastructure implementation with significance values of $0.002<\mathrm{p}<0.001$ and $1.751<\mathrm{z}$ $<1.846$ respectively. The p-values and Z-scores at $\alpha, 0.05$ are within the acceptance region of significance (Howell, 2010). Those with practical LID experience are significantly more likely to encourage, promote, design and build LID infrastructure for runoff control and management.

\section{Discussion}

From the findings, the study established that the perceived risks to LID infrastructure implementation reduce as the individual accumulates years of experience. Some psychological studies point out the fact that risk perception strongly influences the context in which the individuals are when they take their decisions (Slovic, 2000). Such context which may take different forms include past experience. For example, disaster loss mitigation decision through insurance policy (Browne \& Hoyt, 2000; Kunreuther, 1996). Furthermore, past experience on the decision outcomes presentation also positively mediates the framing effects (Kahneman \& Tversky, 1984; Tversky \& Kahneman, 1981). Similarly, Cohen, et.al concluded that individual preferences are no more defined only on decisions but on pairs of decision, and past experience (Cohen et al., 2011). The model of risk aversion characterized by a standard utility function and past experience may be summarized by a sequence of monetary payoffs resulting from the past decisions.

Through the accumulation of experience in a particular discipline or profession, new techniques become familiar as the way of thinking and doing becomes established. For instance, through accumulation of experience over the years, LID project implementation; technical requirements are better put into perspective during planning and designing of future projects which ultimately reduces mistakes of omission that may lead to latent defects causing failures within a short period of time. In addition, accurate overall project cost information can be provided to clients. Provision of such information will allow proper project evaluation before commissioning thus eliminating last minute surprises and project cost overrun. With years of accumulated professional experience, design consultants become attuned to the legislative and other statutory regulations requirements, thus minimising delay in project start off due to non compliance that often delay the approval of development consent applications.

There is a significant difference between individual with LID practical experience versus theoretical knowledge alone on the concern for risk liabilities exposures on LID infrastructure implementation. Individuals with experiential knowledge are in a better position to evaluate options, make better judgment that reduces tension between the polar opposites, and far reaching decisions that reduces potential risk liabilities concerns when it comes to LID project implementation. Construction professionals are often faced with the risks of professional liability which is taken as a breach of the duty of reasonable skill and care in the discharge of their professional responsibilities. If design professionals are sued, courts hold that experts qualified in the field are usually needed to 
determine whether the design professional failed to meet contract obligations or was negligent in carrying out his or her duty. Difficulty with this approach is compounded when an emerging innovation like the LID is involved. With few individuals with LID implementation expertise within the local context of this study, deciding what is reasonable skill and care is difficult and discourages implementation of LID infrastructure for stormwater control and management.

Prior experience has been found to be an important determinant of behaviour (Ajzen, 1991; Fishbein \& Ajzen, 1975). Several conclusions can be inferred from the results of the statistical analysis obtained from this study. First, an individual with previous experience will be more willing to advocate for and sell LID concepts to their clients on their proposed development projects compared to the individual professional with LID theoretical knowledge alone. The difference in the experience-risk perception relationship for professionals has the potential to modify future LID infrastructure adoption behaviours. When professionals are engaged to undertake the design and construction of projects incorporating LID concepts, it may be particularly difficult to get buy-in when majority or the entire team members do not have practical experience. Team collaboration holds potentials to reducing perceived risks of implementation through knowledge integration while equitable risk sharing and allocation between the design team and contractors alike will be helpful in tackling the real contractual risks to advance rate of LID implementation.

Dissemination of relevant information about LID infrastructure is a critical factor in bringing about people's change in attitudes and behaviour in line with the theories of TRA, TPB and TAM to break old habits. Information dissemination influences decisions overcome resistance and encourages behavioural change. Behavioural change communication constitutes an interactive process with communities to develop tailored messages and approaches using a variety of channels that can positively influence attitude; promote and sustain behavioural change in communities (Figueroa et al., 2002). Resistance to LID infrastructure adoption as a result of risk perception can be conceptualised as a cognitive behaviour because information and belief play a role in attitude and social change (Ajzen, 1985; Piderit, 2000). Generally, the process of technology diffusion is anchored on four elements: the innovation, the communication channels, time, and the social system. From the strategic standpoint, researchers have suggested that a sequence of channels helps to maximize the probability of adoption (Mahajan et al., 1990; Rogers, 1995).

Approximately $27 \%$ of registered practitioners surveyed for this study have neither knowledge nor any previous involvement on any projects where LID concepts are suggested, planned or ultimately implemented. Such findings reveal some degree of low level of awareness among practitioners. Practitioners have an important role to play as "champions' and "knowledge navigators" of the process to stimulate community movement towards adoption of LID infrastructure for urban stormwater control. Therefore, to promote LID infrastructure implementation from small-scale to widespread use, relevant and up-to-date information must be communicated through appropriate channels. A tailored channel of influence ensures the dissemination of high-quality information that motivates, builds local wisdom and interactions, and ensure group learning required for the critical mass effect for LID infrastructure. Critical mass defines the fourth model of innovation diffusion networks that incorporates threshold effects. The threshold models of collective behaviour postulate that an individual engages in a behaviour based on the proportion of people within the social system already engaged in the behaviour (Granovetter, 1978; Granovetter \& Soong, 1983). Various channels of influence/communication include word-of-mouth from peers, demonstration/pilot projects, opinion leaders, technical journals and professional reports, and mass media.

The distinctions among these information channels are important because they differ in the ways they accommodate the information processing activities of receivers. Moreover, the effect of a given channel is determined by receivers' access to and the amount of feedback that is provided since the effects of a message on a receiver include attention, comprehension, acceptance, retention, and behavioural change. For instance, word-of-mouth (WOM) is found to play a role in the transmission of information and influence adoption decision because of physical or social proximity (Gaba \& Meyer, 2008). In support of the social network theory, the required tacit knowledge can easily spread through face-to-face interaction or personal relationship. Such interpersonal communication are very effective in forming and changing attitudes that encourage innovation adoption because such proximity engenders trust that are readily transmitted among trusted parties or business associates (Castaldo, 2008). When LID benefits and other information are communicated by WOM among close friends, peers or business associates through an informal settings, linkages between attitude and the perception of risk to implementation is positively mediated (Anderson, 1998; Woodside \& Delozier, 1976). The information are seen as highly credible because the receiver sees the individual conveying the message as independent and not seen to benefit directly from advocating adoption (Silverman, 2001). 
Demonstration projects are at the heart of innovation diffusion and provide the seedbed where innovations are put to practical use and efficiency or performance measured (Clark, 2008; Femenias, 2004). Evaluation of LID pilot projects outcomes increase apparent familiarity which subsequently enhances and facilitates adoption behaviour. For example, design consultants need concise and objective information on the selection of the most appropriate LID systems that will be effective and economically sustainable in meeting the design objectives. To help in reaching these design decisions, information obtained from the evaluation of demonstration projects performance becomes very crucial. Furthermore, demonstration projects provide the foundation for social learning. The social learning theory (also called cognitive or observational learning theory) is the beliefs that people learn by observation before attempting to act (Bandura, 1977, 1986). Learning through such observation lowers the perception of risk to adoption depending on the connectedness of actors within the social network. Moreover, perspective is a direct function of experience, because the two go hand-in-hand with technology adoption (MacDonald, 1998). Monroe and Kaplan also suggested the possibility of pilot projects to serve as effective, sometimes improved, substitutes for direct experience by an individual which may be costly (Monroe \& Kaplan, 1988). Summarily, demonstration projects lay the foundation for reflective practice for construction professionals, provides field for developing mastery and ultimately constitutes the first step in setting the stage for the evolution of LID practice for stormwater control.

Communication through professional associations' technical articles like journals, conference papers or proceedings, and reports provide another medium for innovation information diffusion at a greater rate. Allied construction professionals serve as boundary spanners and key agents in the diffusion of LID knowledge. Members of professional organisation provide expert advice, communication and support during project planning, design and construction to clients and other project team members (Clark \& Staunton, 1989; Lynch, 1989; Scott, 2004; Wellman \& Berkowitz, 1988). From such a casual relationships that existed among professionals, people gain understanding and knowledge expansion by operating on the wealth of documented information derived from personal and vicarious experiences of others. From these interactions, group learning required for the critical mass effect is enhanced (Edmondson et al., 2003; Lawson \& Lorenzi, 1999; Ragna et al., 2004).

According to Rogers's diffusion theory, opinion leaderships are potent agent of innovation diffusion (Rogers, 1995). The strength of opinion leadership's influence as driving force of change is directly linked with the individual status, expertise, experience and the exposure to external sources of information. According to Merton (1957), two types of opinion leaderships are distinguished: monomorphic and polymorphic opinion leaders. Monomorphic opinion leaders exert strong influence in limited area of interest because of their competence, expertise or position. Polymorphic opinion leadership (also called transformational leadership) on the other hand are completely domain-independent which serves as gatekeepers to innovation information, and bridges between different social networks (Wiesner, 2009). Transformation leaders can champion transformation and inspire followers to perform beyond expectations while transcending self-interest for the good of the community (Avolio et al., 2009).

Communications through mass media are more effective at transmitting knowledge of innovation over a wide geographical boundary real time for social representation (Jodelet, 1992). Social representation denotes the way knowledge is shared within an established social context through collective meaning resulting in common cognitions that produces social bonds uniting communities. As a theory of communication, it links society, individual, media, and public. Because media frame have effect for both presentation and comprehension of ideas, it influences our information processing, attitudes, and behaviours that reflect in the idea we support, the way we act, the values we hold, the behaviour we adopt, and the way we perceive reality (Durfee, 2006). Therefore, if appropriate means of information dissemination are developed, risk considered a fundamental barrier to the implementation of LID will be mediated positively.

\section{Conclusions}

The emergence of risk as the principal factor corroborates various concerns raised by the individual interviewed during preliminary study and findings from other disciplines about innovation adoptions. The study established perception of risks and uncertainty have a strong influence on the rate of LID infrastructure adoption and implementation decisions. This study thus contributes to innovation adoption theory by examining the roles of hands-on experience among construction professionals in promoting LID infrastructure for a sustainable urban development. Furthermore, the study identifies a strong need for the disseminations of relevant information considered crucial to changing the perceived risks and misconception among construction professionals. This will advance the network of practitioners that can serve as champions and promoters of the LID concepts in the project development process. 
This study offers insights into the potentials of contractual risk sharing in addressing the real risk associated with implementation of LID infrastructure. Through team collaboration, knowledge can be integrated through the project development process thus ensuring proper implementation that minimises failures. Equitable risk allocation among construction practitioners will build trust, confidence and reduce public resistance. Finally, the limitations of this study which may provide opportunity for future research is acknowledged. First, the empirical results are limited to New Zealand where the LID infrastructure implementation is still emerging. It would be interesting to see comparative studies from other countries, especially the United States where implementation of LID infrastructure is more advanced. Second, the list of potential barriers to LID implementation explored in this study is not exhaustive and warrant further study.

\section{Acknowledgements}

The corresponding author would like to thank The University of Auckland, New Zealand for providing all the facilities in addition to the award of Doctoral Scholarship that made the research leading to this work possible. Any opinions, findings, conclusions, or recommendations in this paper are those of the authors and do not reflect the views of the grantor.

\section{References}

Abhold, K., Loken, L., \& Grumbles, B. (2011). Barriers and Gateways to Green Infrastructures (pp. 36). Washington, DC: Clean Water America Alliance.

Agresti, A. (1996). An Introduction to Categorical Data Analysis. New York: John Wiley \& Sons, Inc.

Ajzen, I. (1985). From Intentions to Actions; A Theory of Planned Behaviour. In J. Juhl, \& J. Beckmann (Eds.), From Cognition to Behavour. New York: Springer.

Ajzen, I. (1991). The Theory of Planned Behaviour. Organizational Behaviour and Human Decision Processes, 50, 179-211. Retrieved from http://people.umass.edu/psyc661/pdf/tpb.obhdp.pdf

Ajzen, I., \& Madden, T. J. (1986). Prediction of Goal-Directed Behavior: Attitudes, Intentions and Perceived Behavioral Control. Journal of Experimental Social Psychology, 22, 453-474. http://dx.doi.org/10.1016/0022-1031(86)90045-4

Al-Bareeq, M. J. (1995). Environmental Pollution and Health. Bahrain Medical Bulletin, 17(4).

Anderson, E. W. (1998). Customer Satisfaction and Word of Mouth. Journal of Service Research, 1(1), 5-17. Retrieved

from http://deepblue.lib.umich.edu/bitstream/2027.42/68654/2/10.1177_109467059800100102.pdf

Andre, T. (2008). Leadership in Sustainable Urban Water Management: An Investigation of the Champion Phenomenon Within Australian Water Agencies (pp. 132). Monash University.

Avolio, B., Walumbwa, F., \& Weber, T. (2009). Leadership: Current Theories, Research, and Future Directions. Annual Review of Psychology, 60, 421-449. http://dx.doi.org/10.1146/annurev.psych.60.110707.163621

Bandura, A. (1977). Social Learning Theory. Englewood Cliffs, New Jersey: Prentice Hall.

Bandura, A. (1986). Social Foundations of Thought and Action: A Social Cognitive Theory. Englewood Cliffs, NJ: Prentice Hall.

Bannerman, R. T., Owens, D. W., Dodds, R. B., \& Hornewer, N. J. (1993). Sources of Pollutants in Wisconsin Stormwater. Journal of Water Science and Technology, 1(28), 241-259.

Beecher, N., Harrison, E., Goldstein, N., Mcdaniel, M., Field, P., \& Sussking, L. (2005). Risk Perception, Risk Communication, and Stakeholder Involvement for Biosolids Management and Research. Journal of Environmental Quality, 34, 122-128. http://dx.doi.org/10.2134/jeq2005.0122

Blockley, D. I., \& Godfrey, P. S. (2000). Doing it Differently. London: Thomas Telford.

Booth, D. B., \& Jackson, C. R. (1997). Urbanization of acquatic Systems: Degradation Thresholds, Stormwater Detection, and the Limits of Mitigation. Journal of the American Water Resources Association, 3(5).

Brown, J., \& Duguid, P. (1991). Organisational Learning and Communities -of-Practice: Toward a Unified View of Working, Learning and Innovation. Journal of Organization Science, 2(1), 40-57. http://dx.doi.org/10.1287/orsc.2.1.40

Brown, J., \& Duguid, P. (2001). Knowledge and Organisation: A Social Practice Perspective. Journal of Organization Science, 12, 198-213. http://dx.doi.org/10.1287/ orsc.12.2.198.10116 
Browne, M., \& Hoyt, R. (2000). The Demand for Food Insurance: Empirical Evidence. Journal of Risk and Uncertainty, 20, 291-306. http://dx.doi.org/10.1023/A:1007823631497

Castaldo, S. (2008). Trust in Market Relationships. Northampton, MA: Edward Elgar Publishing.

Chan, K., \& Carol, K. (2001). Peer Collaboration and Discourse Patterns in Learning from Incompatible Information. Journal of Instructional Science, 29, 443-479. http://dx.doi.org/10.1023/A:1012099909179

Clark, P. A., \& Staunton, N. (1989). Innovation in Technology and Organisation. London: Routledge.

Clark, W. M. (2008). Protecting Florida's Water Quality: Identifying and Overcoming Barriers to Implementation of Low Impact Development (LID) Practices (pp. 6): UF Water Institute.

Cohen, M., Etner, J., \& Jeleva, M. (2011). Dynamic Decision Making when Risk Perception Depends on Past Experience. Retrieved from http://EconPapers.repec.org/RePEc:hal:cesptp:halshs-00211942

Cook, C., Heath, F., \& Russell, T. L. (2000). A Meta-Analysis of Response Rates in Web-or Internet-Based Surveys. Journal of Educational and Psychological Measurement, 60(821), 821-836. http://dx.doi.org/10.1177/0013164002197093

Daley, G. (2011). Gillard Says Australian Floods to Cost $\$ 5.6$ Billion, Levy to Be Imposed, Bloomberg. Retrieved

from

http://www.bloomberg.com/news/2011-01-27/gillard-plans-levy-as-australia-s-worst-flooding-will-cost-5-5 8-billion.html

Darr, D., \& Pretzsch, J. (2008). Mechanisms of Innovation Diffusion Under Information Abundance and Information Scarcity-On the Contribution of Social Networks in Group Vs. Individual Extension Approaches in Semi-Arid Kenya. The Journal of Agricultural Education and Extension, 14(3), 231-248. http://dx.doi.org/10.1080/13892240802207676

Davis, F. D. (1986). A Technology Acceptance Model for Empirically Testing New End-User Information Systems: Theory and Results. PhD, Massachusetts Institute of Technology.

Durfee, J. L. (2006). "Social Change" and "Status Quo" Framing Effects on Risk Perception: An Exploratory Experiment. Science Communication, 27, 459. http://dx.doi.org/10.1177/1075547005285334

Eason, C. T., Feeney, C., Van Roon, M., Keenan, B., \& Craig, J. (2003). Providing Incentives for Low-Impact Development to Become Mainstream. Paper presented at the The 3rd South Pacific Conference on Stormwater and Aquatic Resource Protection, NZWWA, Auckland. Retrieved from http://www.landcareresearch.co.nz/publications/researchpubs/EasonE79.pdf

Edmondson, A. C., Winslow, A. B., Bohmer, R. J., \& Pisano, G. P. (2003). Learning How and Learning What: Effects of Tacit and Codified Knowledge on Performance Improvement Following Technology Adoption. Decision Science, 34(2), 1-27. http://dx.doi.org/10.1111/1540-5915.02316

Farrelly, M., \& Brown, R. (2009). Demonstration Projects: Case Studies from Melbourne, Australia (pp. 32). Melbourne: Monash University.

Femenias, P. (2004). Demonstration Projects for Sustainanable Building; Towards a Strategy for Sustainable Development in Building Sector Based on Swedish and Dutch Experience. PhD, Chalmers University of Technology, Sweden, Goteborg.

Field, A. (2006). Discovering Statistics Using SPSS: and Sex, Drugs rock " $n$ " Roll (2nd ed.). Thousand Oaks, California, USA: Sage Publications.

Figueroa, M. E., Kincaid, D. L., Rani, M., \& Lewis, G. (2002). Communication for Social Change: An Integrated Model for Measuring the Process and its Outcomes. New York: The Rockefeller Foundation.

Fishbein, M., \& Ajzen, I. (1975). Belief, Attitude, Intention and Behaviour: An Introduction to Theory and Research. Reading, MA: Adison-Wesley Publishing Co.

Gaba, V., \& Meyer, A. (2008). Crossing the Organizational Species Barrier: How Venture Capital Practices Infiltrated the Information Technology Sector. Journal of Academic Management, 51, 976-998.

Garside, J. (2012). Thailand flooding costs Lloyd's of London \$2.2bn, The Guardian, p. 24. Retrieved from http://www.guardian.co.uk/business/2012/feb/14/lloyds-thailand-flooding-2bn-dollars

Granovetter, M. (1978). Threshold Model of Collective Behaviour. The American Journal of Sociology, 83(6), 1420-1443. http//:links.jstor.org/sici?=0002-9602\%28197805\%2983\%3A6\%3C1420\%3ATMOCB\%3E2.0.CO\%3B2-8 
Granovetter, M., \& Soong, R. (1983). Threshold Models of Diffusion and Collective Behavior. The Journal of Mathematical Sociology, 9(3), 165-179. http://dx.doi.org/10.1080/0022250X.1983.9989941

Haile, R. W., Witte, J. S., Gold, M., Ron, C., McGee, C., Millikan, R. C., ... Wang, G. (1999). The Health Effects of Swimming in Ocean Water Contaminated by Storm Drain Runoff. Epidemiology, 10(4), 355-363. http://dx.doi.org/10.1097/00001648-199907000-00004

Howell, C. D. (2010). Statistical Methods for Psychology (7th ed.). Belmont, California: Cengage Wadsworth.

Jeng-Bulloch, S. K. (2011). Cost-Benefit Allocation of Selected Low Impact Development Techniques Versus the Conventional Method. PhD, University of Houston, Texas.

Jodelet, D. (1992). Social Representations. Naples: Liguori.

Kahneman, D., \& Tversky, A. (1984). Choices, Values, and Frames. American Psychologist, 39(4), 341-350. Retrieved from http://dirkbergemann.commons.yale.edu/files/kahnemann-1984-choices-values-frames.pdf

Khan, Z. (1998). Risk Premiums Associated With Exculpatory Clauses. Master, University of Calgary, Canada, Alberta.

Kloss, C., \& Calarusse, C. (2006). Rooftops to Rivers: Green Strategies for Controlling Stormwater and Combined Sewer Overflows. Maryland: Natural Resources Defense Council, Low Impact Development Center, and University of Maryland School of Public Policy.

Konrad, C. P., \& Booth, D. B. (2005). Hydrologic Changes in Urban Streams and their Ecological Significance. In R. G. LR Brown, RM Hughes, \& MR Meadors (Eds.), Effect of Urbanization of Stream Ecosystems (pp. 157-177). American Fisheries Society, Bethesda, MD.

Kunreuther, H. (1996). Mitigation of Disaster Losses through Insurance. Journal of Risk and Uncertainty, 12, 171-187. http://dx.doi.org/10.1007/BF00055792

Kunz, A., Dehlin, S., Piazza, T., Fjeld, M., \& Olofsson, T. (2010). Collaborative Whiteboard: Towards Remote Collaboration and Interaction in Construction Design. Paper presented at the Proceedings of the CIB W78 2010 27th International Conference Cairo, Egypt.

Ladson, A. R., Walsh, C. J., \& Fletcher, T. D. (2006). Improving Stream Health in Urban Areas by Reducing Runoff Frequency from Impervious Surfaces. Australian Journal of Water Resources, 10, 23-34.

Lawson, C., \& Lorenzi, E. (1999). Collective Learning, Tacit Knowledge in Group Innovation. California Management Review, 33(4), 305-317.

Lindner, R. K. (1987). Adoption and Diffusion of Technology: An Overview. Paper presented at the Technological Change in Post-harvest Handling and Transportation of Grains in the Humid Tropics, Australia.

Little, R. J. A., \& Rubin, D. B. (2002). Statistical Analysis with Missing Data (2nd ed.). Hoboken, New Jersey: Wiley.

Lynch, J. (1989). Looking Overseas for New Members. Association Management, 110-115.

MacDonald, S. (1998). Information for Innovation: Managing Change from an Information Perspective. New York: Oxford University Press.

Mahajan, V., Muller, E., \& Bass, F. M. (1990). New Product Diffusion Models in Marketing: A Review and Directions for Research. Journal of Marketing, 54, 1-26. Retrieved from http://marketingscience.info/assets/documents/210/4045.pdf

Michael, E. D. (2007). Low Impact Development Practices: A review of Current Research and Recommendations for Future Directions. Water Air Soil Pollut, 186, 351-363. http://dx.doi.org/10.1007/s11270-007-9484-z

Monroe, M. C., \& Kaplan, S. (1988). When Words Speak Louder Than Actions: Environmental Solving in the $\begin{array}{lllll}\text { Classroom. Journal of Environmental } & \text { Education, } & 19, & 38-41 .\end{array}$ http://dx.doi.org/10.1080/00958964.1988.9942762

Munkvoid, E. B. (2002). Implementation of Collaboration Technologies in Industry: Case Examples and Lessons Learned. Great Britain: Springer. 
Paul, M. J., \& Meyer, J. L. (2001). Streams in the Urban Landscape. Annual Reveiw of Ecology and Systematics, 32, 333-365. Retrieved from http://www.uri.edu/cels/nrs/whl/Teaching/nrs592/2009/ Class\%209\%20Stream\%20Legacies\%20and\%20disturbance/Paul\%20Meyer\%20Urban\%20streams.pdf

Piderit, S. K. (2000). Rethinking Resistance and Recognizing Ambivalence: A Multidimensional View of Attitudes Towards an Organisational Change. The Academy of Management Review, 25(4), 783-794. Retrieved from http://www.jstor.org/stable/259206

Ragna, S. A., Hartmann, E., Kearney, A. T., \& Gemunded, H. G. (2004). The Role of Tacit Knowledge in Innovation Management. Paper presented at the Copetitive Paper Submitted to the 20th Annual IMP Conference, Copenhagen.

Rogers, E. (1995). Diffusions of Innovation (4th ed.). New York: The Free Press.

Rubin, D. B. (1976). Inference and Missing Data. Biometrika, 63(3), 581-592. http://dx.doi.org/10.1093/biomet/63.3.581

Schafer, J. L., \& Graham, J. W. (2002). Missing data: Our View of the State of the Art. Journal of Psychological Methods, 7, 147-177. http://dx.doi.org/10.1037/1082-989X.7.2.147

Scott, J. (2004). Social Network Analysis (2nd ed.). London: Sage Publications.

Shaver, E. (2009). Low Impact Design Versus Conventional Development; A literature Review of Developer-Related Costs and Profit Margins (pp. 41). Auckland: Aqua Terra International Ltd.

Siegel, S., \& Castellan, N. J. (1988). Nonparametric Statistics for the Behavioural Sciences (2nd ed.). New York: McGraw-Hill.

Silverman, G. (2001). Secrets of Word-of-Mouth Marketing. New York, USA: AMACOM Books.

Sinharay, S., Stern, H. S., \& Russell, D. (2001). The Use of Multiple Imputation for the Analysis of Missing Data. Journal of Psychological Methods, 6, 317-329. http://dx.doi.org/10.1037/1082-989X.6.4.317

Slovic, P. (2000). The Perception of Risk. London and Sterling: Earthscan Publications Ltd.

Tabachnick, B. G., \& Fidell, L. S. (2007). Using Multivariate Statistics. Boston, USA: Pearson Education. Inc.

Tagliaventi, M. R., \& Mattarelli, E. (2006). The Role of Networks of Practice, Value Sharing, and Operational Proximity in Knowledge Flows Between Professional Groups. Human Relations, 59(3), 291-319. http://dx.doi.org/10.1177/0018726706064175

Taylor, S., \& Todd, P. (1995). Assessing IT usage: The Role of Prior Experience. MIS Quarterly, 19(4), 561-570. http://dx.doi.org/10.2307/249633

Tetra Tech Inc. (2002). Cost Comparison of Conventional and Low Impact Development Designs for Medium Density Residential Site in Huntersville, North Carolina. Chapell Hill, North Carolina: Tetra Tech.

Tetra Tech Inc. (2003a). Cost Comparison of Conventional and Low Impact Development Designs for High Density Residential Site in Huntersville, North Carolina. Chapell Hill, North Carolina: Tetra Tech.

Tetra Tech Inc. (2003b). Cost Comparison of Conventional and Low Impact Development Designs for the Ranson Road School Site in Huntersville, North Carolina Chapell Hill, North Carolina: Tetra Tech.

Tsur, Y., Sternberg, M., \& Hochman, E. (1990). Dynamic Modeling of Innovation Process Adoption with Risk Aversion and Learning. Oxford Economic Papers, 42, 336-355.

Tversky, A., \& Kahneman, D. (1981). The Framing of Decisions and the Psychology of Choice. Science, 211(4481), 453-458. Retrieved from http://www.jstor.org/stable/1685855

Valente, T. W. (1995). Network Models of the Diffusion of Innovation. New Jersey: Hampton: Cresskill.

Vreede, G. J., \& Briggs, R. O. (2005). Collaboration Engineering: Designing Repeatable Processes for High-Value Collaborative Tasks. Paper presented at the 38th Hawaiian International Conference of System Sciences, Los Alamitos, Hawaii, USA. http://dx.doi.org/10.1109/HICSS.2005.144

Wellman, B., \& Berkowitz, S. D. (1988). Social Structures: A Network Approach. New York, USA: Cambridge University Press.

White, G. (2011). Devastating Australian Floods To Cost Country \$5 Billion, Business Insider. Retrieved from http://articles.businessinsider.com/2011-01-06/markets/30088324_1_devastating-floods-gdp-queensland 
Wiesner, A. (2009). Opinion Leadership and Social Influence in Online Environments. PhD, University of Erlangen, Nürnberg.

Wildavsky, A., \& Dake, A. (1990). Theories of Risk Perception; Who Fears What and Why? Deadalus, 119(4), 41-60. Retrieved from http://www.jstor.org/stable/20025337

Woodside, A. G., \& Delozier, M. W. (1976). Effect of Word of Mouth Advertising on Consumer Risk Taking. Journal of Advertising, 5(4), 12-19.

Young, P. H. (2009). Innovation Diffusion in Heterogeneous Populations: Contagion, Social Influence, and Social Learning. American Economic Review, 99(5), 1899-1924. Retrieved from www.aeaweb.org/articles.php?doi=10.1257/aer.99.5.1899

Zaghloul, R., \& Hartman, F. (2003). Construction Contracts: The Cost of Mistrust. International Journal of Project Management, 21(6), 419-424. http://dx.doi.org/10.1016/S0263-7863(02)00082-0 